\title{
Smoking Cessation During Pregnancy Among Roma and Non-Roma Women in Hungary's Underdeveloped Regions*
}

\author{
Péter Balázs, Andrea \\ Fogarasi-Grenczer \\ Semmelweis University, \\ Budapest, Hungary
}

\author{
Ildiko Rákóczi \\ Debrecen-Nyíregyháza University, \\ Nyíregyháza, Hungary
}

\author{
Kristie L. Foley \\ Davidson College, \\ Davidson, USA
}

\begin{abstract}
Lower socioeconomic status is correlated with higher tobacco use worldwide. Using a retrospective cohort design, we conducted in-person surveysamong womenliving in Hungary's underdeveloped regions to evaluate their smoking habits before, during, and after pregnancy. Forty-one percent $(n=6,351)$ of respondents with known smoking statusand ethnicity $(n=15,592)$ smoked prior to pregnancy, $26.5 \%$ were self-identified Roma and $73.5 \%$ were non-Roma. During pregnancy, two third (65.8\%) continued to smoke, although significant differences were observed across ethnicities. Roma women were nearly twice as likely to continue smoking as non-Roma women (98.3\% vs. 50.5\%, respectively). Using biometric and socioeconomic characteristics, we determined the associations of different factors with smoking habits separately for these two populations. We then assessed how these factors contributed to continued smoking during the pregnancy controlling for ethnicity. These results are essential while tailoring tobacco cessation programs for ethnic minoritieswho live in unfavorable socioeconomic circumstances.
\end{abstract}

Keywords: tobacco smoking and pregnancy, Roma ethnic minority, cessation during pregnancy

\section{Introduction}

The national smoking prevalence of the adult female population in Hungary was estimated between 23\%-33\% in 2012 (Forey, Hamling, Hamling, Thornton, \& Lee, 2013). Deep poverty, limited formal education, weak economic activity, and social exclusion of ethnic minorities have a serious negative impact on smoking prevalence especially in the underdeveloped northeastern and southeastern regions of this country. The underdeveloped regions of Hungary are disproportionately Roma, the largest ethnic minority in the country. Among Roma women Kósa (2012) found heavy smoking prevalence with approximately $25 \%$ of women aged 8-29 years and $49 \%$ of women aged 30-44 years smoking at least one pack per day. As a result of multiple stress-inducing factors (such as social isolation), mental health of Roma is not only worse than that of the general

\footnotetext{
* Sponsorship: This publication was based on the research project supported by the Fogarty International Centre, the National Cancer Institute and the National Institutes on Drug Abuse within the National Institutes of Health (Grant Number 1 R01 TW007927-01).

Péter Balázs, Ph.D., Institute of Public Health, Semmelweis University.

Andrea Fogarasi-Grenczer, C.F.N.P., Department of Family Care Methodology, Semmelweis University.

Ildiko Rákóczi, C.F.N.P., Faculty of Health, Nyíregyháza, Division of Health Care and Prevention, Debrecen-Nyíregyháza University.

Kristie L. Foley, Ph.D., professor and associate director, Medical Humanities Program, Davidson College.
} 
population but also worse than that of ethnic majority groups who live under similar socioeconomic conditions (Kósa, 2012).

A recent American study of pregnancy cohorts (Keyes, March, Link, Chilcoat, \& Susser, 2013) demonstrated that gradients of socioeconomic position strongly emerge across these cohorts rather than time alone. In our present study, before controlling for poverty, the proportion of pre-pregnancy smoking was $40.7 \%$, separately $56.1 \%$ in the Roma and $35.2 \%$ in the non-Roma, which exceeds the Hungarian national female average. When stratifying by poverty status, $57.4 \%$ of Roma women living in deep poverty were smokers.

Based on a large sample $(n=21,248)$, maternal smoking is clearly related to increased relative risk of LBW (low birth weight) and PTB (preterm birth) of babies (Koet al. 2013). In Hungary, the average prevalence of LBW was $8.6 \%$ and that of PTB 8.8\% in 2010-2012 (Statistical Yearbook of Hungary, 2012). In our comparably large initial sample of women with live-born babies without stratifying for ethnicity $(n=18,633)$, the prevalence of LBW was $9.3 \%$ that of PTB $8.6 \%$. When controlled for continued smoking during pregnancy, the proportion of LBW was $16.6 \%$ and that of PTB $12.8 \%$.

Unfortunately, there are no precise domestic demographic data about the Roma. The last census conducted in 2011 indicated a 315,000 minority population (Census National Data, 2011). However, the European Union Framework for National Roma Integration Strategies up to 2020 contains semi-officially estimated data (European Commission, 2011). Within the European Union, Hungary has the fourth largest estimated Roma population (7.05\%) after Bulgaria (10.33\%), the Slovak Republic $(9.17 \%)$ and Romania (8.32\%). According to this document, the average estimated number of Roma in Hungary is 700,000 (more than twice what was reported in the 2011 census). In the north-eastern region of the country, according to the estimates of the 2011 census, Roma comprise approximately $6.0 \%-8.5 \%$, while in the south-eastern region approximately $1.5 \%-2.9 \%$.

There are numerous studies concerning the poor health status of the European especially the Central European Roma population (Parekh \& Tamsin, 2011; Fésüs, Östlin, McKeec, \& Ádány, 2012; Kolarcik, Madarasova, Orosova, van Dijk, \& Reijneveld, 2009; Vokó et al., 2009; Kósa, Lénárt, \& Ádány, 2002; Kósa et al., 2007; Hujová et al., 2010). Targeted studies were also published about the reproductive health of Roma women (Bobak, Dejmek, Solansky, \& Sram, 2005; Rambouskova, Dlouchy, Krizova, Prochazka, Hrncirova, \& Andel, 2009; Foley, Balázs, Grenczer, \& Rákóczi, 2011). According to Bobak et al. (2005), 73\% of pregnant Roma women were smoking prior to the pregnancy and $63 \%$ continued the habit during the full gestation period. Rambusková et al. (2009) found in a relatively small sample (76 Roma versus 156 non-Roma women) 85.5\% smoking prevalence among Roma and 57.9\% continued smoking during the pregnancy.

Considerable differences in smoking prevalence between Roma and non-Roma women and the corresponding LBW and PTB differentials between the minority and majority ethnic groups emphasize the importance of properly adapted tobacco cessation programs in Hungary's underdeveloped north-eastern and south-eastern counties. As a recent review of the concerning literature demonstrated, behavioral interventions to promote smoking cessation in ethnic minorities need to be culturally adapted to be more effective. Thus, more systematic studies are needed to gain insight in diverse populations for establishing the best cultural adaptations of cessation programs (Nierkens et al., 2013).

In Hungary, there is a special MCHC (maternity and child health care) service with precinct-based nurses for regions with an average population of 2,000 or greater. MCHC nurses are responsible for pre-pregnancy, prenatal and postnatal care of womenduring their reproductive years. They are also trained to provide minimal intervention for tobacco cessation for smoking womenas soon as women register their pregnancy with the 
MCHC service. The government is supporting this program primarily in underdeveloped regions. However, notable differences in PTB and LBW proportions among ethnic groups illustrate the need for more effectivemotivational interventionsto reduce tobacco use among the Roma minority population. The aim is rather complexas a recent comprehensive review of the literature indicated that there isno clear evidence of the effectiveness of culturally-adapted smoking cessation interventions in ethnic minority groups (Liu et al., 2013).

This study provides descriptive data on the obstetrical history, demographic, socioeconomic and sociocultural specialities and differences of smoking status among Roma and non-Roma pregnant women. Using these data, we assessed positive and negative factors for quitting when women learned they were pregnant. Given that pregnancy is a unique period in a woman's life, one when they would be highly motivated to quit smoking, it is essential to understand the multiplicity of social, economic, and cultural factors that contribute to tobacco use during pregnancy.

\section{Materials and Methods}

Human subjects' approval of our survey was provided by the ethics committee of Semmelweis University in Budapest, Hungary. We conducted a retrospective cohort study of women who delivered live born babies in 2009-2012. The target area was the underdeveloped northeastern and southeastern parts of the country in a former region with considerable Roma population. Local MCHC nurses while using their registers of pregnant and delivered women contacted the target population, which is a census of all births during the timeframe ( $n=$ 24,979). All contacts were made twice. Ultimately, $74.59 \%(n=18,633)$ consented to participate in the study.Including women for whom smoking status and ethnicity were known, the sample was reduced to 15,592 . Of these women, 6,351 (40.7\%) smoked prior to the pregnancy and comprise our analytical sample.

Our research study consisted of two parts, with a total of 131 items in seven categories. The first part contained questions to be answered by the local MCHC nurses based on their own medical registers. These data include: age of mother, biometric data of mothers (weight in $\mathrm{kg}$ in the first trimester and height in $\mathrm{cm}$ ) and basic data of obstetrical history. Among historical data, we collected information about the number of prior pregnancies, PTBs, and spontaneous and artificial abortions. Body mass index (BMI $=\mathrm{kg} / \mathrm{m}^{2}$, i.e., body mass in kilogram divided by height in meters squared) was converted to a categorical variable (BMI underweight $\leq$ 18.49 , normal weight $=18.5-24.9$, overweight $=25-29.9$, obese $=30$ or greater). We dichotomized prior pregnancies as two or more versus zero or one.

Among socioeconomic and cultural variables, basic education means eight elementary school classes or less, non-married status is a comprehensive definition for contractual and non-contractual cohabitation and single mothers respectively. Participants without employment included all persons who receive different social benefits, disabled and students. There is no legal poverty level in Hungary, i.e., it is not a part of the legislation on the actual yearly budget of the central government. Instead, there is a statistical poverty level published annually by the Central Statistical Office of the country and is generally used as a proxy for economic status of the population. Based on the OECD standard, $50 \%$ (in the European Union $60 \%$ ) of the median income equals the income poverty level. The median income/month/consumption unit increased from HUF 60,000 in 2009 to 84,000 in 2012 (TÁRKI Social Research Institute Inc., 2013). Deep poverty level was defined as $<50 \%$ of the average value. We defined housing without amenities as no connection to the water supply mains, to the sewage system, nor operational individual heating. Concerning dietary and lifestyle habits, only $0.9 \%$ of the whole sample $(n=18,633)$ admitted drinking alcohol (beer or wine) once a week or more often. ETS (environmental 
tobacco smoke) was defined as noexposure, versus daily exposure by a husband or partner in confined spaces. Because our intent was to assess factors associated with quitting during pregnancy, we conducted all analyses only among women who indicated they smoked prior to pregnancy. We used $t$-probe for controlling ethnic distribution, ORs (odds ratios) with 95\% confidence interval (95\% CI) to show the relative importance of ethnicity in selected socioeconomic and cultural characteristics and binary logistic regression to assess factors associated with continuing versus quitting tobacco use during the pregnancy (significance level, $p \leq 0.05$ ).

\section{Results}

In the analyzed sample of women who smoked prior to the pregnancy $(n=6,351)$, there were $36.5 \%$ Romaand $(n=2,321), 63.5 \%$ non-Roma $(n=4,030)$. The overall proportion of smoking during pregnancy was $66.7 \%$, but there were considerable ethnic differences; $89.3 \%$ of Roma were smoking during the pregnancy compared to $50.5 \%$ of non-Roma. Given the difference in smoking rates during pregnancy, we calculated bivariate associations biometric, obstetrical, demographic, socioeconomic, cultural, and lifestyle variables related to the Roma versus non-Roma ethnicity (see Table 1). Although all differences were significant at $p<$ 0.05 , divergences were the greatest between Roma and non-Roma in the following areas, with Roma being at a greater disadvantage: educational level $(\mathrm{OR}=21.2)$, being unemployed $(\mathrm{OR}=17.55)$ and living indeep poverty $(\mathrm{OR}=12.82)$ followed by housing without amenities. Concerning dietary habits, Roma had reduced consumption of fruit ( $\mathrm{OR}=3.38)$, vegetables $(\mathrm{OR}=2.64)$, dairy products $(\mathrm{OR}=2.51)$, and meat $(2.51)$. Roma were twice as likely as non-Roma to beunderweight. Being unmarried was more typical among pregnant Roma women ( $\mathrm{OR}=3.07)$, as was being young $(\mathrm{OR}=5.73)$, and having a non-intended pregnancy $(\mathrm{OR}=3.28)$. ETS impact by husband or partner in confined spaces was nearly five times $(\mathrm{OR}=4.70)$ as likely among Roma versus non-Roma respondents. Finally, Roma respondents were more likely to have had a prior pregnancy (OR $=2.34)$ and more likely to have had a previous PTB $(\mathrm{OR}=1.51)$, spontaneous abortion $(\mathrm{OR}=1.26)$ and artificial abortion $(\mathrm{OR}=1.43)$.

Table 1

Bivariate Associations of Roma Versus Non-Roma Women Smoking Prior to the Pregnancy by Biometric, Socioeconomic, and Life-Style Variables $(n=6,351)$

\begin{tabular}{lccc}
\hline Variables & OR & $95 \%$ CI & $p$-value \\
\hline $\begin{array}{l}\text { Roma } v s . \text { non-Roma }(2,321 / 4,030) \\
\text { Age } 17 \text { or less } v s \text {. older }(198 / 6,153)\end{array}$ & 5.73 & $4.12-7.97$ & $<0.001$ \\
$\begin{array}{l}\text { Roma } v s . \text { non-Roma }(2,238 / 3,902) \\
\text { BMI underweight } v s \text {. all others }(752 / 6,905)\end{array}$ & 2.04 & $1.74-2.39$ & $<0.001$ \\
$\begin{array}{l}\text { Roma } v s . \text { non-Roma }(2,278 / 3,940) \\
\text { Non-intended } v s . \text { intended pregnancy }(2,620 / 3,598)\end{array}$ & 3.28 & $2.94-3.65$ & $<0.001$ \\
$\begin{array}{l}\text { Roma } v s . \text { non-Roma }(2,283 / 3,961) \\
\text { Prior pregnancies } \text { or more } v s . \text { less }(3,883 / 2,361)\end{array}$ & 2.34 & $2.09-2.61$ & $<0.001$ \\
$\begin{array}{l}\text { Roma } v s . \text { non-Roma }(2,292 / 3,999) \\
\text { Prior PTB } v s . \text { at term birth }(662 / 5,629)\end{array}$ & 1.51 & $1.29-1.78$ & $<0.001$ \\
$\begin{array}{l}\text { Roma } v s . \text { non-Roma }(2,315 / 4,020) \\
\text { Prior spontaneous abortion yes/no }(1,103 / 5,232)\end{array}$ & 1.26 & $1.07-1.40$ & 0.003 \\
$\begin{array}{l}\text { Roma } v s . \text { non-Roma }(2,313 / 4,016) \\
\text { Prior artificial abortion yes/no }(1,684 / 4,645)\end{array}$ & 1.43 & $1.27-1.60$ & $<0.001$ \\
$\begin{array}{l}\text { Roma } v s . \text { non-Roma }(2,413 / 4,697) \\
\text { Basic education } v s . \text { higher }(3,119 / 3,991)\end{array}$ & 21.2 & $18.43-24.50$ & $<0.001$ \\
$\begin{array}{l}\text { Roma } v s . \text { non-Roma }(2,309 / 4,011) \\
\text { Non married } v s . \text { married }(3,891 / 2,429)\end{array}$ & 3.07 & $2.74-3.45$ & $<0.001$ \\
\hline
\end{tabular}


(Table 1 to be continued)

\begin{tabular}{llcc}
\hline Variables & OR & $95 \%$ CI & $p$-value \\
\hline $\begin{array}{l}\text { Roma } v s . \text { non-Roma }(2,304 / 4,015) \\
\text { No-employment } v s . \text { employed }(4,161 / 2,158)\end{array}$ & 17.55 & $14.55-21.20$ & $<0.001$ \\
$\begin{array}{l}\text { Roma } v s . \text { non-Roma }(2,268 / 3,875) \\
\text { Deep poverty } v s . \text { all others }(3,368 / 2,775)\end{array}$ & 11.43 & $9.96-13.11$ & $<0.001$ \\
$\begin{array}{l}\text { Roma } v s . \text { non-Roma }(2,218 / 3,769) \\
\text { Housing without amenities } v s . \text { all others }(975 / 5,012)\end{array}$ & 6.46 & $5.54-7.54$ & $<0.001$ \\
$\begin{array}{l}\text { Roma } v s \text {. non-Roma }(2,304 / 4,015) \\
\text { Fruits every 3rd day or less } v s . \text { more often }(1,616 / 4,703)\end{array}$ & 3.38 & $3.01-3.80$ & $<0.001$ \\
$\begin{array}{l}\text { Roma } v s . \text { non-Roma }(2,303 / 4,013) \\
\text { Vegetables every 3rd day or less } v s . \text { more often }(1,831 / 4,485)\end{array}$ & 2.64 & $2.36-2.95$ & $<0.001$ \\
$\begin{array}{l}\text { Roma } v s . \text { non-Roma }(2,301 / 4,013) \\
\text { Dairy every 3rd day or less } v s . \text { more often }(1,262 / 5,052)\end{array}$ & 2.51 & $2.22-2.85$ & $<0.001$ \\
$\begin{array}{l}\text { Roma } v s . \text { non-Roma }(2,289 / 4,002) \\
\text { Meat every 3rd day or less } v s . \text { more often }(1,194 / 5,097)\end{array}$ & 1.51 & $1.33-1.72$ & $<0.001$ \\
$\begin{array}{l}\text { Roma } v s . \text { non-Roma }(2,276 / 3,976) \\
\text { Coffee at least every other day } v s . \text { less often }(4,227 / 2,025)\end{array}$ & 1.69 & $1.51-1.90$ & $<0.001$ \\
$\begin{array}{l}\text { Roma } v s . \text { non-Roma }(2,242 / 3,908) \\
\text { ETS by partner yes/no }(2,344 / 3,806)\end{array}$ & 4.70 & $4.21-5.26$ & $<0.001$ \\
\hline
\end{tabular}

The multivariable analysis (see Table 2) shows the contribution of the same variables (inclusive the Roma versus non-Roma ethnicity) in smoking cessation during the pregnancy. The dependent variable was defined as $1=$ "Continued to smoke" or 0 = "Quit smoking". Prior legal abortion, housing circumstances, dietary habits related to fruit, vegetable and meat consumption did not have any significant impact on smoking habit during the pregnancy. The strongest influence on continued smoking was indicated by the lack of more than basic education $(\mathrm{OR}=3.05)$, the ETS generated by husband or partner of the pregnant woman $(2.98)$, and drinking coffee at least every day $(\mathrm{OR}=1.95)$. The strongest impact on smoking cessation was age $\leq 17$ years $(\mathrm{OR}=$ $0.10)$ and beingunderweight $(\mathrm{OR}=0.55)$. Self-identified Roma women were twice as likely to continue smoking during pregnancyalso $(\mathrm{OR}=2.02)$. Related to obstetrical history, prior PTB $(\mathrm{OR}=0.65)$ and spontaneous abortion $(\mathrm{OR}=0.67)$ were associated with a reduced likelihood of continued smoking.

Table 2

Binarylogistic Regression of Biometric, Socioeconomic, and Life-Style Factors for Tobacco Smoking Cessation During the Pregnancy $(n=4,517)$

\begin{tabular}{llll}
\hline Variables & OR & $95 \%$ CI & $p$-value \\
\hline Roma $v s$. non-Roma & 2.03 & $1.64-2.51$ & $<0.001$ \\
Age 17 or less $v s$. older & 0.10 & $0.08-0.14$ & $<0.001$ \\
BMI underweight $v s$. all others & 0.55 & $0.44-0.70$ & $<0.001$ \\
Non-intended $v s$. intended pregnancy & 1.40 & $1.18-1.65$ & $<0.001$ \\
Prior pregnancies 2 or more $v s$. less & 1.53 & $1.27-1.85$ & $<0.001$ \\
Prior PTB $v s$. at term birth $(718 / 6,348)$ & 0.65 & $0.52-0.83$ & $<0.001$ \\
Prior spontaneous abortion yes/no $(5,878 / 1,234)$ & 0.67 & $0.55-0.82$ & $<0.001$ \\
Prior legal abortion yes/no $(1,805 / 5,302)$ & 0.87 & $0.72-1.05$ & 0.152 \\
Basic education $v s$. higher $(3,119 / 3,991)$ & 3.05 & $2.49-3.74$ & $<0.001$ \\
Non married $v s$. married $(4,105 / 2,993)$ & 1.48 & $1.25-1.74$ & $<0.001$ \\
No-employment $v s$. employed $(4,434 / 2,668)$ & 1.54 & $1.28-1.85$ & $<0.001$ \\
Deep poverty $v s$. all others $(3,507 / 3,371)$ & 1.60 & $1.33-1.92$ & $<0.001$ \\
Housing without amenities $v s$. all others $(997 / 5,717)$ & 1.07 & $0.82-1.39$ & 0.610 \\
Fruits every 3rd day or less $v s$. more often $(1,671 / 5,423)$ & 1.61 & $0.93-1.47$ & 0.185 \\
Vegetables every 3rd day or less $v s$. more often $(1,943 / 5,148)$ & 1.16 & $0.94-1.42$ & 0.165 \\
\hline
\end{tabular}


(Table 2 to be continued)

\begin{tabular}{llll}
\hline Variables & OR & $95 \%$ CI & $p$-value \\
\hline Dairy every 3rd day or less $v s$. more often $(1,329 / 5,759)$ & 0.69 & $0.56-0.85$ & $<0.001$ \\
Meat every 3rd day or less $v s$. more often $(1,292 / 5,774)$ & 0.88 & $0.72-1.08$ & 0.237 \\
Coffee at least every other day $v s$. less often $(4,550 / 2,478)$ & 1.95 & $1.65-2.29$ & $<0.001$ \\
ETS by partner yes/no $(2,397 / 4,509)$ & 2.98 & $2.48-3.57$ & $<0.001$ \\
\hline
\end{tabular}

\section{Discussion}

This study proved striking differences in smoking habits between Roma and non-Roma women prior to and after pregnancy in Hungary's underdeveloped regions. Concerning the serious negative impact of tobacco smoking not only on maternal but neonatal health, we assessed factors of cessation during the pregnancy as a formative step in designing effective interventions.

Age $\leq 17$ years and BMI underweight proved to be strong protective factors. Among young girls, the success of cessationis most likely explained by a shorter duration of smoking.In addition, there is evidence that cessation results in body weight gain (Basterra-Gortari et al., 2010). Additionally, women are more prone to the belief that smoking controls weight (McKee, Nhean, Hinson, \& Mase, 2006). BMI underweight $(\leq 18.49)$ is not a desired condition for the well-being of the mother or baby, nevertheless, women who are underweight may be less concerned than normal or overweight women about pregnancy-related weight gain. Thus, they may be more likely to quit.

In our study, unintended pregnancy correlated significantly with continued smoking. In the USA, half of pregnancies are unintended and only half of all women who smoke cigarettes are able to quit during pregnancy (Chisolm, Cheng, \& Terplan, 2014). Consequently, if cessation programs fail among fertile women, pregnancy intention must be a distinct indicator for cessation support during the pregnancy. Concerning the obstetrical history, prior legal abortion seems to have no significant impact on quitting tobacco smoking. However, prior PTB, and spontaneous abortion should be used as a powerful supportive factor in smoking cessation interventions timed to the pre- and early pregnancy care given that pregnant women want to ensure a successful pregnancy and healthy baby.

Limited education (eight or less elementary classes) with lower perceived risk to the fetus is a generally well-established predictor of continuing smoking during pregnancy. Yet, low levels of education have an important impact in the underdeveloped regions of Hungary. In our sample, the overall proportion of lower education was $47.6 \%$; when stratified by ethnicity, however, clear disparities emerge. $87.5 \%$ and $24.7 \%$ of Roma and non-Roma women respectively have completed 8 grades or less of school. One could argue that keeping girls in school could be as (or more) important for ensuring the well-being of young girls (e.g., reducing unplanned pregnancies, reducing tobacco use, reducing maternal and neonatal health problems). It is also important to recognize the rise of non-marital childbearing and the growth of cohabitation. In the initial sample, the proportion of marriedwomen was $38.4 \%$ compared to cohabitant couples $61.6 \%$. Thus, we agree with findings that continuing to smoke throughout the pregnancy is not a result of loneliness, but rather the lack of an intimate (marital) relationship (Kiernana \& Pickett, 2006).

Concerning the socioeconomic status and contrasted to a recent study targeting African American women (Kendzor et al., 2012), our findings reaffirm previous research that unemployment and deep povertyare significant predictors of continued smoking during the pregnancy. However, because of the difference in samples between the Kendzor et al. (2012) study and ours, we can conclude that deep poverty among pregnant 
women was definitely not associated with greater odds of quitting for economic reasons.

A specific study of smoking and non-smoking pregnant women's dietary habits indicated significant differencesto the smokers' disadvantage in reduced intake only of milk product and vegetables (Ortega, Martines, Lopez-Sobaler, Andres, \& Quintas, 1998). In our sample, reduced intake of dairy products was the only positive factor of smoking cessation. Considering the lack of data based on great samples in the literature correlating dietary and tobacco use behaviors during pregnancy, there is a clear need for surveys that address multiple lifestyle risk behaviors in a single project. Nevertheless, eating habits are for many reasons hardly comparable across nations and geographic regions thus related studies will only locally be relevant is smoking cessation interventions. Frequent coffee consumption was strongly interrelated with tobacco smoking. Among women who continued smoking, $76.6 \%$ drank coffee at least every other day.

ETS generated by partner was the second most important negative factor for not quitting during the pregnancy. It highlights the need to include smoking partners in studies hoping to reduce tobacco smoking during pregnancy (Ockene et al., 2002). Moreover, the lack of meaningful differences in the relationship between Roma and non-Roma and ETS exposure, suggests that family-based interventions are needed across all ethnic groups. The nature of this inclusion is critical because, e.g., only a booklet distributed for smoking partners about the commitment of the father to the pregnancy (quitting together would make a substantial positive impact on the health of the baby) had no effect on partners' smoking (de Vries, Bakker, Dolan Mullen, \& van Breukelen, 2006). Innovative techniques (telephone interviews, involving the participants' local general practitioner and controlling carbon monoxide levels in the participants' home)were effective and suggested to be more widely adopted (Stanton, Lowe, Moffatt, \& Del Mar, 2004).

We are aware of limitations of our study for three main reasons. First, there was a relatively high percentage $(10.0 \%)$ of pregnant women's initial sample $(n=18,633)$ who did not self-identify their ethnicity. This might have biased the results of the study. Secondly, all pregnant women experienced a short minimal intervention for smoking cessation by their own MCHC nurses. Spontaneous cessation of smoking was reported by $28 \%$ in the USA among low-income pregnant women (Ockene et al., 2002). Without relevant data, we cannot estimate the potential for spontaneous cessation in our sample because all women received "something" (although the exact nature of the delivery of motivational interviewing was not measured). Third, outcomes of the multivariable analysis must be considered carefully because the individual decision for cessation is a result of numerous intellectual and emotional motivations based on past experiences. Additionally, each of our variables unifies many background factors in a simplified manner for practical reasons. It is true also for the ethnicity variable. Consequently, we believe that ethnicity should be part of the multiple factors that are considered when tailoring cessation interventions for pregnant women.

\section{References}

Basterra-Gortari, F. J., Forga, L., Bes-Rastrollo, M., Toledo, L., Martínez, J. A., \& Martínez-Gonzáleza, M. A. (2010). Effect of smoking on body weight: Longitudinal analysis of the SUN cohort. Revista Española de Cardiología (English Edition), 63, $20-27$.

Bobak, M., Dejmek, J., Solansky, I., \& Sram, R. J. (2005). Unfavourable birth outcomes of the Roma women in the Czech Republic and the potential explanations: A population-based study. BMC Public Health, 5, 106-111.

Census National Data, 2011 (2013). Budapest, Central Statistical Office of Hungary. Retrieved from http://www.ksh.hu/docs/hun /xftp/idoszaki/nepsz2011/nepsz_orsz_2011.pdf

Chisolm, M. S., Cheng, D., \& Terplan, M. (2014). The relationship between pregnancy intention and change in perinatal cigarette smoking: An analysis of PRAMS data. Journal of Substance Abuse Treatment, 46, 189-193. 
de Vries, H., Bakker, M., Dolan Mullen, P., \& van Breukelen, G. (2006). The effects of smoking cessation counseling by midwives on Dutch pregnant women and their partners. Patient Education and Counseling, 63, 177-187.

European Commission. (2011). An EU framework for national roma integration strategies up to 2020: Communication from the Commission to the European Parliament, the Council, the European Economic and Social Committee and the Committee of the Regions. Retrieved from http://ec.europa.eu/justice/policies/discrimination/docs/com_2011_173_en.pdf

Fésűs, G., Östlin, P., McKeec, M., \& Ádány, R. (2012). Policies to improve the health and well-being of Roma people: The European experience. Health Policy, 105, 25-32.

Foley, L. K., Balázs, P., Grenczer, A., \& Rákóczi, I. (2011). Factors associated with quit attempts and quitting among Eastern Hungarian women who smoked at the time of pregnancy. Central European Journal of Public Healt, 19, 63-66.

Forey, B., Hamling, J., Hamling, J., Thornton, A., \& Lee, P. (2013). International smoking statistics, Web edition, a collection of worldwide historical data, Hungary, 2013. Retrieved from: http://www.pnlee.co.uk/Downloads/ISS/ISS-Hungary_131105. pdf

Hujová, Z., Alberty, R., Ahlers, I., Ahlersová, E., Paulíková, E., Desatniková, J. et al. (2010). Cardiovascular risk predictors in central Slovakian Roma children and adolescents: Regional differences. Central European Journal of Public Health, 18, 139-144.

Kendzor, D. E., Reitzel, L. R., Mazas, C. A., Cofta-Woerpel, L. M., Cao, Y., Ji L. et al. (2012). Individual- and area-level unemployment influence smoking cessation among African Americans participating in a randomized clinical trial. Social Science \& Medicine, 74, 1394-1401.

Keyes, K. M., March, D., Link, B. G., Chilcoat, H. D., \& Susser, E. (2013). Do socio-economic gradients in smoking emerge differently across time by gender? Implications for the tobacco epidemic from a pregnancy cohort in California, USA. Social Science \& Medicine, 76, 101-106.

Kiernana, K., \& Pickett, K. E. (2006). Marital status disparities in maternal smoking during pregnancy, breastfeeding and maternal depression. Social Science \& Medicine, 63, 335-346.

Ko, T. J., Tsai, L. Y., Chu, L. C., Yeh, S. J., Leung, C., Chen, C. Y. et al. (2013). Parental smoking during pregnancy and its association with low birth weight, small for gestational age, and preterm birth offspring: A birth cohort study. Pediatrics and Neonatology. Retrieved from http://ac.els-cdn.com/S1875957213001058/1-s2.0-S1875957213001058-main.pdf?_ tid=162a9a 0e-76ca-11e3-b8c3-00000aacb360\&acdnat=1389009791_52fc4a2926360da1c846fad9875bebae

Kolarcik, P., Madarasova, G. A., Orosova, O., van Dijk, J. P., \& Reijneveld, S. A. (2009). To what extent does socioeconomic status explain differences in health between Roma and non-Roma adolescents in Slovakia? Social Science \& Medicine, 68, 1279-1284.

Kósa, K., Lénárt, B., \& Ádány, R. (2002). Health status of the Roma population in Hungary (in Hungarian language). OrvosiHetilap, 143, 2419-2426.

Kósa, K. (2012). Mental health of Roma people. Népegészségügy, 90, 264-268.

Kósa, Z., Széles, G., Kardos, L., Kósa, K., Német, R., Országh, S. et al. (2007). A comparative health survey of the inhabitants of Roma settlements in Hungary. American Journal of Public Health, 97, 853-859.

Liu, J. J., Wabnitz, C., Davidson, E., Bhopal, R. S., White, M., Johnson, M. R. D. et al. (2013). Smoking cessation interventions for ethnic minority groups-A systematic review of adapted interventions. Preventive Medicine, 57, 765-775.

McKee, S. A., Nhean, S., Hinson, R. E., \& Mase, T. (2006). Smoking for weight control: Effect of priming for body image in female restrained eaters. Addictive Behaviors, 31, 2319-2323.

Nierkens, V., Hartman, M. A., Nicolaou, M., Vissenberg, C., Beune, E. J. A. J., Hosper, K. et al. (2013). Effectiveness of cultural adaptations of interventions aimed at smoking cessation, diet, and/or physical activity in ethnic minorities: A systematic review. PLoS ONE: e73373. doi:10.1371/journal.pone.0073373.

Ockene, J. K., Ma, Y., Zapka, J. G., Pbert, L. A., Goins, K. V., \& Stoddard, A. M. (2002). Spontaneous cessation of smoking and alcohol use among low-income pregnant women. American Journal of Preventive Medicine, 23, 150-159.

Ortega, R. M., Martines, R. M., Lopez-Sobaler, P. A., Andres, P., \& Quintas, M. E. (1998). The consumption of food, energy and nutrients in pregnant women: Differences with respect to smoking habits. Nutrition Research, 18, 1691-1701.

Parekh, N., \& Tamsin, R. (2011). Health inequalities of the Roma in Europe: A literature review. Central European Journal of Public Health, 19, 139-142.

Rambouskova, J., Dlouchy, P., Krizova, E., Prochazka, B., Hrncirova, D., \& Andel, M. (2009). Health behaviors, nutritional status, and anthropometric parameters of Roma and non-Roma mothers and their infants in the Czech Republic. Journal of Nutrition Education and Behavior, 41, 58-64. 
Stanton, W. R., Lowe, J. B., Moffatt, J., \& Del Mar, C. B. (2004). Randomized control trial of a smoking cessation intervention directed at men whose partners are pregnant. Preventive Medicine, 38, 6-9.

Statistical Yearbook of Hungary. (2012). Budapest: Central Statistical Office, Budapest.

TÁRKI Social Research Institute Inc.. (2013). Egyenlötlenségéspolarizálódás a magyartársadalomban. Inequalities and polarization in the Hungarian society. Budapest, TÁRKI, 2013. Retrieved from: http://www.tarki.hu/hu/research/ $\mathrm{hm} /$ monitor2012 teljes.pdf

Vokó, Z., Csépe, P., Németh, R., Kósa, K., Kósa, Z., Széles, G. et al. (2009). Does socioeconomic status fully mediate the effect of ethnicity on the health of Roma people in Hungary? Journal of Epidemiology and Community Health, 63, 455-460. 